\title{
High Serum Uric Acid and High-Sensitivity C Reactive Protein Concentrations Predict Three- Year Cardiovascular Mortality in Patients Treated With Continuous Ambulatory Peritoneal Dialysis
}

\author{
Quyen Dao Bui Quy ${ }^{1}$, Tuan Pham Ngoc Huy ${ }^{2}$, Tuan Nguyen Minh ${ }^{3}$, Loc Nguyen Duc ${ }^{4}$, Tuan Nguyen Minh \\ ${ }^{5}$, Kien Nguyen Trung ${ }^{6}$, Tien Tran Viet ${ }^{7}$, Quyet Do ${ }^{8}$, Thang Le Viet ${ }^{9}$ \\ 1. Nephrology, Cho Ray Hospital, Ho Chi Minh, VNM 2. Intensive Care Unit, Trung Vuong Hospital, Ho Chi Minh, VNM \\ 3. Hemodialysis, Cho Ray Hospital, Ho Chi Minh, VNM 4. Nephrology, An Sinh Hospital, Ho Chi Minh, VNM 5. Urology, \\ E Hospital, Hanoi, VNM 6. Hematology and Blood Transfusion, Military Hospital 103, Hanoi, VNM 7. Director, Military \\ Hospital 103, Hanoi, VNM 8. Director, Vietnam Military Medical University, Hanoi, VNM 9. Nephrology and \\ Hemodialysis, Military Hospital 103, Hanoi, VNM
}

Corresponding author: Thang Le Viet, lethangviet@yahoo.co.uk

\begin{abstract}
Aims: This study aims to access the predicting value of serum uric acid (UA) and high-sensitivity C reactive protein (hs-CRP) concentration on three-year cardiovascular-related mortality in patients performing continuous ambulatory peritoneal dialysis (CAPD).
\end{abstract}

Methods: A total of 267 CAPD patients [150 male (56.2\%); mean age $48.93 \pm 13.58$ years] were included in our study. All patients had measured serum UA and hs-CRP concentration. A high-sensitivity particleenhanced immunoturbidimetric assay determined serum hs-CRP; serum UA levels were determined using an enzymatic colorimetric assay. All patients were followed for three years to detect cardiovascular-related mortality by cardiologists and stroke specialists.

Results: Mean serum UA level was $415.16 \pm 84.28 \mu \mathrm{mol} / \mathrm{L}, 58.4 \%$ of patients had increased serum UA level. Median serum hs-CRP level was $2(1-4) \mathrm{mg} / \mathrm{L}, 12.4 \%$ of patients had increased serum hs-CRP level. During 36 months of follow-up, 41 patients (15.4\%) had cardiovascular-related mortality. The results of Cox proportional hazards regression showed that hypertension, diabetes, high serum UA and hs-CRP were risk factors that related to cardiovascular-related mortality ( $\mathrm{p}<0.05)$. The receiver operating characteristic (ROC) curve and Kaplan-Meier analysis results showed that UA and hs-CRP level had predictive value for threeyear cardiovascular-related mortality in CAPD patients [uric acid: area under the curve (AUC) $=0.822$; hsCRP: $\mathrm{AUC}=0.834, \mathrm{p}<0.001]$.

Conclusion: High serum UA and hs-CRP levels were predictive factors of cardiovascular-related mortality in CAPD patients.

Review began 08/13/2021 Review ended 09/11/2021 Published 09/12/2021

\section{๑) Copyright 2021}

Dao Bui Quy et al. This is an open access article distributed under the terms of the Creative Commons Attribution License CC-BY 4.0., which permits unrestricted use, distribution, and reproduction in any medium, provided the original author and source are credited.
Categories: Internal Medicine, Nephrology, Therapeutics

Keywords: capd, uric acid, hs-crp, cardiovascular-related mortality, predicting

\section{Introduction}

Peritoneal dialysis (PD) is one of the most common kidney replacement therapies. Peritoneal dialysis is performed by using a catheter to infuse sterile solution into the peritoneal cavity. The peritoneum is used as an exchange filter to remove solutes [1-3]. PD consists of two methods: continuous ambulatory and automated PD, in which continuous ambulatory PD (CAPD) is widely used in Vietnam. A mortality rate in CAPD from $8.3 \%$ to $39.2 \%$ was reported in previous studies [4-6]. Prolonged use of CAPD is related to a higher mortality rate $[4,6]$, in which mortality due to cardiovascular events was behind infection-related ones.

C-reactive protein (CRP) is synthesized mainly in the liver and released into the bloodstream in response to an acute phase of tissue damage or infection. Many studies have also shown that some factors such as for overweight, elderly, hypertension, diabetes, smoking, and other cardiovascular risks also affect hs-CRP levels [7-10]. In PD patients, elevated hs-CRP levels are related to higher cardiovascular events and mortality [11-13]. Uric acid (UA) is a purine metabolism production in humans. Elevated serum uric acid concentration is related to the appearance of cardiovascular events such as hypertension, coronary heart disease, stroke and the elevation of mortality rate [14-16]. High serum UA was also confirmed as one of the risk factors for cardiovascular events and PD patients' mortality [17-20]. PD is a typical renal replacement therapy in Vietnam. Up to now, there is no research in Vietnam on prevalence as well as risk factors relating to cardiovascular-related mortality in CAPD patients. For these reasons, we performed this study to access the predictive values of serum UA and hs-CRP for cardiovascular-related mortality during three years follow- 


\section{Cureus}

up in Vietnamese CAPD patients.

The Ethical Committee of Cho Ray Hospital has approved this study (No.1378/QĐ/BVCR). All human procedures followed the local ethical standards and the Helsinki Declaration of 1975 (revised in 2008). All patients signed written informed consent before participating in this study.

\section{Materials And Methods \\ Study design}

A total of 384 CAPD patients participated in our study at the Department of Nephrology, Cho Ray Hospital, Ho Chi Minh City, Vietnam, from March 2016 to March 2019. We excluded 117 patients who had one of the exclusion criteria such as age under 18 years old, duration of $\mathrm{PD}<$ two months, on hemodialysis treatment or who had kidney transplantation before initiation of PD, peritonitis, acute illness, a sign of infection (hs-CRP $\geqslant 10 \mathrm{mg} / \mathrm{L}$; white blood cell count $\geqslant 10 \mathrm{G} / \mathrm{L}$; or neutrophil percentage $\geqslant 70 \%$ ), malignancies, transfer to other dialysis units (loss of follow-up), non-cardiovascular-related mortality, etc. The remaining 267 patients (150 male and 117 female) were selected and signed informed consent before participation in this study. A flowchart of the study is presented in Figure 1.

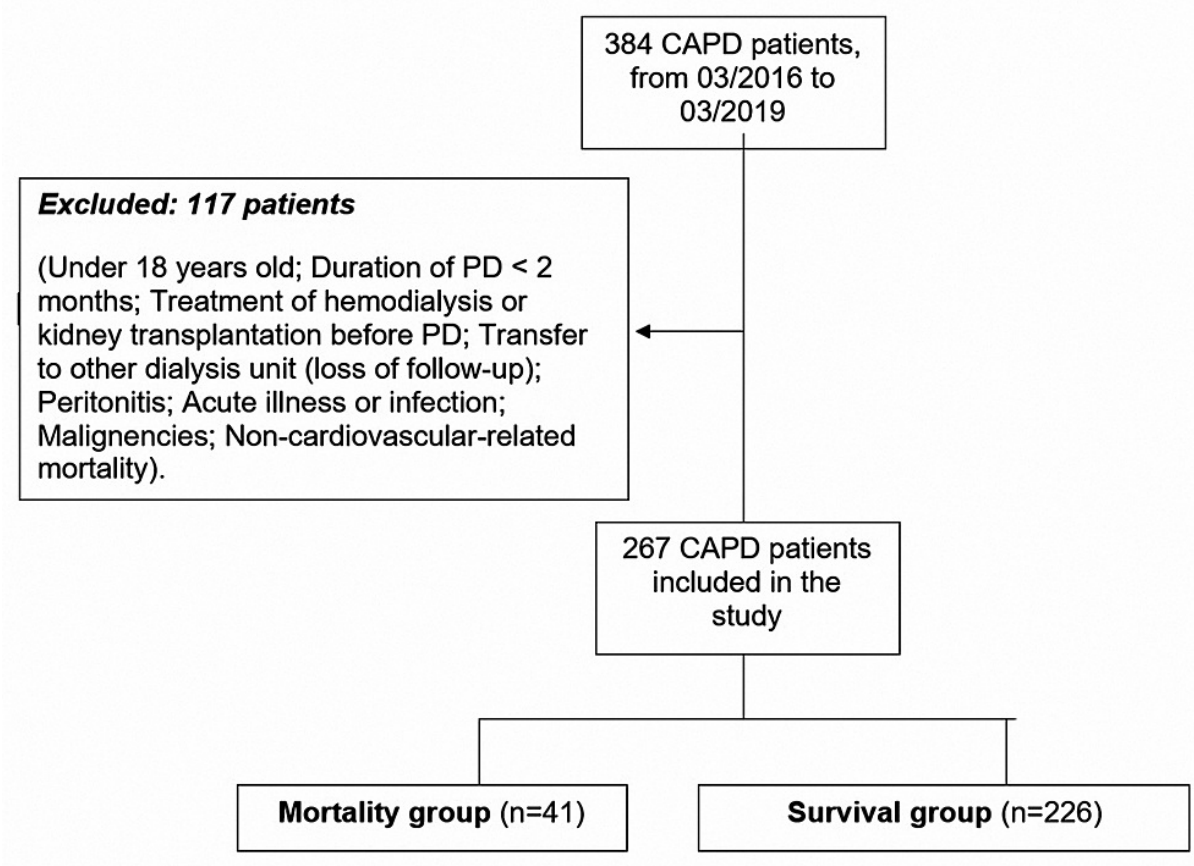

FIGURE 1: Study population and analyzed groups

PD: peritoneal dialysis, CAPD: continuous ambulatory peritoneal dialysis

All patients had 24-hour urine volume collected and measured. Creatinine clearance (CCr) week, Kt/V week and peritoneal equilibration test (PET) were also measured. We used the dialysate to the plasma concentration ratio of creatinine (D/Pcreat) to evaluate the peritoneal small solute transport rate. Based on Twardowski's 1987 classification, PET is classified into four levels [21] as follows: high (H: D/Pcreat $\geqslant 0.81)$, high-average (HA: D/Pcreat 0.65-0.80), low-average (LA: D/Pcreat 0.51-0.64), and low (L: D/Pcreat $\leqslant 0.5$ ) transporters.

We collected all demographic data in baseline time (includes: age, gender, time of peritoneal dialysis, measuring height, weight, calculating BMI, etc.). Blood was taken to measure necessary hematological and biochemical indices by standard laboratory methods. Serum samples were collected by standard venepuncture during the first annual visit post-HTx, frozen samples (stored at $-80^{\circ} \mathrm{C}$ ) were available for 267 patients. All biochemical analyses, including glucose, creatinine, urea, albumin, protein, and electrolyte parameters, were measured by an automatic analyzer. Levels of serum hs-C-reactive protein were determined by a high-sensitivity particle-enhanced immunoturbidimetric assay [Tina-quant C-reactive protein (Latex) High Sensitive (Roche Diagnostics, Basel, Switzerland)] with an inter-assay variance $<10 \%$ in the range 0.1-300 mg/L. Serum uric acid levels were determined using an enzymatic colorimetric assay (Roche Uric Acid Plus; Roche Diagnostics). The measuring range was $12-3720 \mu \mathrm{mol} / \mathrm{L}$, with imprecision coefficients of variation of $<2.3 \%$. 


\section{Cureus}

Diabetes was diagnosed according to the patient's history of diabetes, or two subsequent analyzes showed fasting blood glucose levels $\geqslant 7.0 \mathrm{mmol} / \mathrm{L}$. Hypertension was diagnosed in patients who regularly used antihypertensive drugs to control blood pressure or had at least two times blood pressure $\geqslant 140 / 90 \mathrm{~mm} \mathrm{Hg}$. Anemia was diagnosed when hemoglobin $<130 \mathrm{~g} / \mathrm{L}$ in males or $<120 \mathrm{~g} / \mathrm{L}$ in females. We calculated residual renal creatinine clearance $(\mathrm{ClCr})$ as the average of renal urea and creatinine clearances, indexing to body surface area [22]. Lipid disorder was diagnosed based on the 2013 KDIGO guideline [23].

\section{Follow-up and outcomes}

We followed up to detect death from cardiovascular causes (Cardiovascular cause mortality in our patients was defined as death attributable to myocardial ischemia and infarction, heart failure, cardiac arrest, or cerebrovascular accident [24]) for 36 months. All of these events were confirmed by cardiologists and stroke specialists.

\section{Statistical analyses}

We processed and analyzed data by the Statistical Package for Social Science (SPSS) version 20.0 (IBM Corp., Armonk, NY, USA). We used Student's t-test to compare two mean values of continuous normal-distribution data and Mann-Whitney U test to compare two median values of non-normal distribution data. We used the Chi-square test to compare two groups of categorical data. The Cox proportional hazards regression analysis was performed to determine risk factors of mortality after three years' follow-up. We performed the receiver operating characteristic (ROC) curves model and the Kaplan-Meier analysis to determine the mortality predicting the value of hs-CRP, uric acid, and prealbumin after three years' follow-up. A p-value $<0.05$ was considered significant.

\section{Results}

In Table 1 , the patient's mean age was $48.93 \pm 13.58$ years $(56.2 \%$ male, $16.1 \%$ diabetic mellitus $(\mathrm{DM})$, and 83.1\% hypertension). The median PD duration was 21 months. The proportion of lost residual kidney function and anemia was $71.9 \%$ and $95.5 \%$, respectively. The mean serum UA was $415.16 \pm 84.28 \mu \mathrm{mol} / \mathrm{L}$, with a $58.4 \%$ increase. The median serum hs-CRP was $2.0 \mathrm{mg} / \mathrm{L}$, with a $12.4 \%$ increase, and $15.4 \%$ of patients died cardiovascular cause during three years.

\section{Clinical characteristics and laboratory parameters}

Ages (years)

Number of males $(n, \%)$

PD duration (month)

Hypertension ( $n, \%)$

Diabetic mellitus $(n, \%)$

BMI $\left(\mathrm{kg} / \mathrm{m}^{2}\right)$

$\mathrm{BMI}<18.5(\mathrm{n}, \%)$

BMI: $18.5-22.9$ (n, \%)

$\mathrm{BMI} \geq 23(\mathrm{n}, \%)$

Residual kidney function (n,\%)

24-hours urine volume $(\mathrm{ml})$

D4/P

PET H (n, \%)

PET HA (n, \%)

PET LA (n, \%)

PET L (n, \%)

Serum urea $(\mathrm{mmol} / \mathrm{L})$

Creatinine $(\mu \mathrm{mol} / \mathrm{L})$

$\mathrm{Kt} / \mathrm{V}$

Mean \pm SD/ Median
$48.93 \pm 13.58$
N/A
$21(10-41)$
N/A
N/A
$21.21 \pm 2.95$
N/A
N/A
N/A

n, $\%$

N/A

$150(56.2)$

N/A

$222(83.1)$

43 (16.1)

N/A

$44(16.5)$

160 (59.9)

63 (23.6)

N/A

75 (28.1)

$180(130-500)$

N/A

$0.7 \pm 0.08$

N/A

N/A

$20(7.5)$

N/A

166 (62.2)

N/A

$78(29.2)$

N/A

$3(1.1)$

$19.34 \pm 6.14$

N/A

774.37 (654.9 - 955.8)

N/A

$1.98 \pm 0.3$ 


\section{Cureus}

\begin{tabular}{|c|c|c|}
\hline Total CCr (L/week/1.73m²) & $62.6 \pm 9.32$ & N/A \\
\hline Hemoglobin (g/L) & $100.14 \pm 17.01$ & N/A \\
\hline Anemia $(n, \%)$ & $\mathrm{N} / \mathrm{A}$ & $255(95.5)$ \\
\hline WBC (G/L) & $6.88 \pm 1.49$ & N/A \\
\hline Neutrophil (G/L) & $61.36 \pm 8.52$ & N/A \\
\hline Glucose (mmol/L) & $4.22(3.77-4.83)$ & N/A \\
\hline $\mathrm{Na}+(\mathrm{mmol} / \mathrm{L})$ & $136.92 \pm 3.75$ & N/A \\
\hline $\mathrm{K}+(\mathrm{mmol} / \mathrm{L})$ & $3.68 \pm 0.78$ & N/A \\
\hline Ca++ (mmol/L) & $2.05 \pm 0.3$ & N/A \\
\hline Protein (g/dL) & $6.51 \pm 0.7$ & N/A \\
\hline Albumin (g/dL) & $3.68 \pm 0.48$ & N/A \\
\hline Prealbumin (mg/dL) & $0.34 \pm 0.08$ & N/A \\
\hline Uric acid ( $(\mu \mathrm{mol} / \mathrm{L})$ & $415.16 \pm 84.28$ & N/A \\
\hline Increase uric acid $(n, \%)$ & N/A & $156(58.4)$ \\
\hline hs-CRP (mg/L) & $2(1-4)$ & N/A \\
\hline Increase hs-CRP $(n, \%)$ & N/A & 33 (12.4) \\
\hline Mortality (n,\%) & N/A & $41(15.4)$ \\
\hline
\end{tabular}

\section{TABLE 1: Baseline demographic and laboratory characteristics of patients}

PD: Peritoneal Dialysis; BMI: Body Mass Index; PET: Peritoneal Equilibration Test; H: High; HA: High-Average; LA: Low-Average; L: Low; CCr: Creatinine clearance; WBC: White Blood Cell; hs-CRP: high sensitive C Reactive Protein.

In mortality patients, the ratio of diabetes, the mean UA, and the median hs-CRP concentration was significantly higher than those of the survival group, while the mean prealbumin concentration was lower than those of the survival group ( $\mathrm{p}<0.05)$ (Table 2).

\begin{tabular}{|c|c|c|c|}
\hline Clinical characteristics and laboratory parameters & Mortality group $(n=41)$ & Survival group $(\mathrm{n}=226)$ & p \\
\hline Ages (years) & $47.98 \pm 12.91$ & $49.1 \pm 13.72$ & 0.628 \\
\hline Number of male $(n, \%)$ & $27(65.9)$ & $123(54.4)$ & 0.175 \\
\hline PD duration (month) & $24(15.5-43.5)$ & $19(9-39.25)$ & 0.22 \\
\hline Hypertension (n,\%) & $30(73.2)$ & $192(85)$ & 0.064 \\
\hline Diabetic mellitus $(\mathrm{n}, \%)$ & $17(41.5)$ & 26 (11.5) & $<0.001$ \\
\hline BMI $\left(\mathrm{kg} / \mathrm{m}^{2}\right)$ & $22.33 \pm 3.78$ & $21 \pm 2.74$ & 0.038 \\
\hline BMI < 18.5 & $5(12.2)$ & 39 (17.3) & \multirow{3}{*}{0.04} \\
\hline BMI: $18.5-22.9$ & $20(48.8)$ & $140(61.9)$ & \\
\hline $\mathrm{BMI} \geq 23$ & $16(39)$ & $47(20.8)$ & \\
\hline 24-hour urine volume (ml) & $165(117.5-600)$ & $180(130-500)$ & 0.681 \\
\hline Residual kidney function & $12(29.3)$ & $63(27.9)$ & 0.855 \\
\hline D4/P & $0.71(0.62-0.75)$ & $0.73(0.62-0.77)$ & 0.187 \\
\hline PET H $(n, \%)$ & $3(7.3)$ & $17(7.5)$ & \\
\hline PET HA $(n, \%)$ & $22(53.7)$ & $144(63.7)$ & 0.529 \\
\hline
\end{tabular}




\section{Cureus}

\begin{tabular}{|c|c|c|c|}
\hline PET LA $(n, \%)$ & $15(36.6)$ & $63(27.9)$ & \\
\hline PET L (n,\%) & $1(2.4)$ & $2(0.9)$ & \\
\hline Serum urea (mmol/L) & $21.62 \pm 5.13$ & $18.93 \pm 6.23$ & 0.01 \\
\hline Creatinine $(\mu \mathrm{mol} / \mathrm{L})$ & $831.9(699.15-982.35)$ & $761.1(643.61-955.8)$ & 0.226 \\
\hline $\mathrm{Kt} / \mathrm{V}$ & $1.95 \pm 0.33$ & $1.99 \pm 0.3$ & 0.47 \\
\hline Total CCr (L/week/1.73m²) & $61.45 \pm 11.29$ & $62.81 \pm 8.93$ & 0.393 \\
\hline Hemoglobin (g/L) & $104.16 \pm 12.5$ & $99.41 \pm 17.63$ & 0.1 \\
\hline Anemia $(n, \%)$ & $40(97.6)$ & $215(95.1)$ & 0.49 \\
\hline WBC (G/L) & $7.03 \pm 1.56$ & $6.85 \pm 1.48$ & 0.472 \\
\hline Neutrophil (\%) & $61.1 \pm 10.4$ & $61.4 \pm 8.16$ & 0.836 \\
\hline Glucose (mmol/L) & $4.22(3.75-4.75)$ & $4.19(3.81-4.84)$ & 0.898 \\
\hline $\mathrm{Na}+(\mathrm{mmol} / \mathrm{L})$ & $137.09 \pm 3.44$ & $136.89 \pm 3.8$ & 0.745 \\
\hline $\mathrm{K}+(\mathrm{mmol} / \mathrm{L})$ & $3.87 \pm 0.78$ & $3.64 \pm 0.78$ & 0.094 \\
\hline Ca++ (mmol/L) & $2.09 \pm 0.36$ & $2.04 \pm 0.29$ & 0.372 \\
\hline Protein (g/dL) & $6.59 \pm 0.88$ & $6.5 \pm 0.66$ & 0.448 \\
\hline Albumin (g/dL) & $3.77 \pm 0.45$ & $3.67 \pm 0.49$ & 0.222 \\
\hline Prealbumin (mg/dL) & $0.3 \pm 0.07$ & $0.34 \pm 0.08$ & 0.005 \\
\hline Uric acid ( $\mu \mathrm{mol} / \mathrm{L})$ & $502.7 \pm 105.63$ & $399.28 \pm 69.02$ & $<0.001$ \\
\hline Increase uric acid $(n, \%)$ & $35(85.4)$ & 121 (53.5) & $<0.001$ \\
\hline hs-CRP (mg/L) & $5.1(3.1-5.65)$ & $2(1-3.6)$ & $<0.001$ \\
\hline Increase hs-CRP (n,\%) & $21(51.2)$ & $12(5.3)$ & $<0.001$ \\
\hline
\end{tabular}

\section{TABLE 2: Comparison of demographic and laboratory characteristics between mortality and}

survival group

PD: Peritoneal Dialysis; BMI: Body Mass Index; PET: Peritoneal Equilibration Test; H: High; HA: High-Average; LA: Low-Average; L: Low; CCr: Creatinine clearance; WBC: White Blood Cell; hs-CRP: high sensitive C Reactive Protein.

The results of Cox proportional hazards regression in Table 3 showed that various risk factors were related to mortality, including hypertension, diabetes, high serum UA and hs-CRP ( $\mathrm{p}<0.05)$.

\begin{tabular}{|c|c|c|c|}
\hline Variable & HR & $95 \% \mathrm{Cl}$ & $\mathbf{p}$ \\
\hline Hypertension & 2.051 & $1.011-4.157$ & 0.046 \\
\hline Diabetes & 0.361 & $0.187-0.698$ & 0.002 \\
\hline Increase uric acid ( $\mu \mathrm{mol} / \mathrm{L})$ & 0.282 & $0.117-0.679$ & 0.005 \\
\hline Increase hs-CRP (mg/L) & 0.091 & $0.047-0.175$ & $<0.001$ \\
\hline
\end{tabular}

\section{TABLE 3: Cox proportional hazards regression analysis to determine risk factors of mortality} hs-CRP: high sensitive C Reactive Protein. 


\section{Cureus}

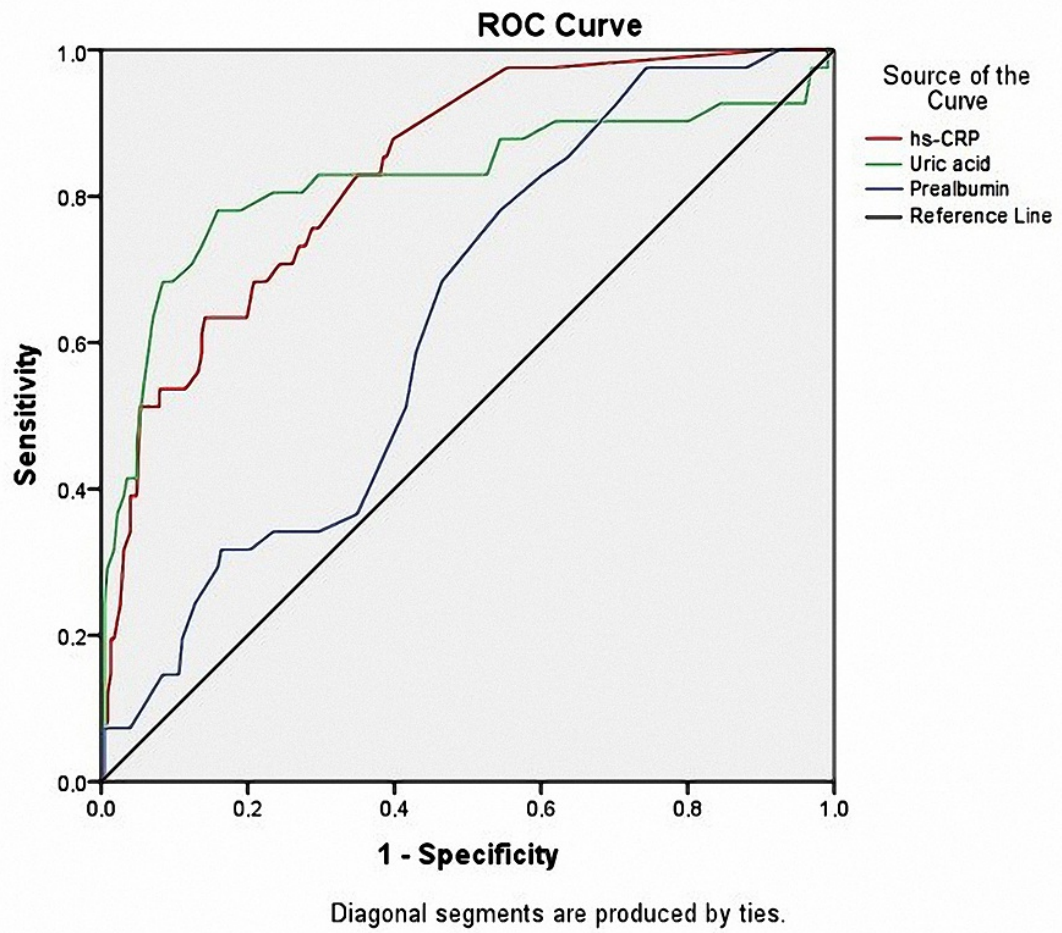

FIGURE 2: Receiver operating characteristics (ROC) curve of prealbumin, hemoglobin, serum UA, and hs-CRP to predict mortality.

UA: uric acid; hs-CRP: high-sensitivity $C$ reactive protein

The Kaplan-Meier analysis in Figure 3 showed that patients with higher serum UA level (UA $\geqslant 467.07 \mu \mathrm{mol} / \mathrm{L}$ : red line) had a significantly higher mortality rate than those with lower UA level (UA $<467.07 \mu \mathrm{mol} / \mathrm{L}$ : violet line) (Log-rank test, $\mathrm{p}<0.001)$. 


\section{Cureus}

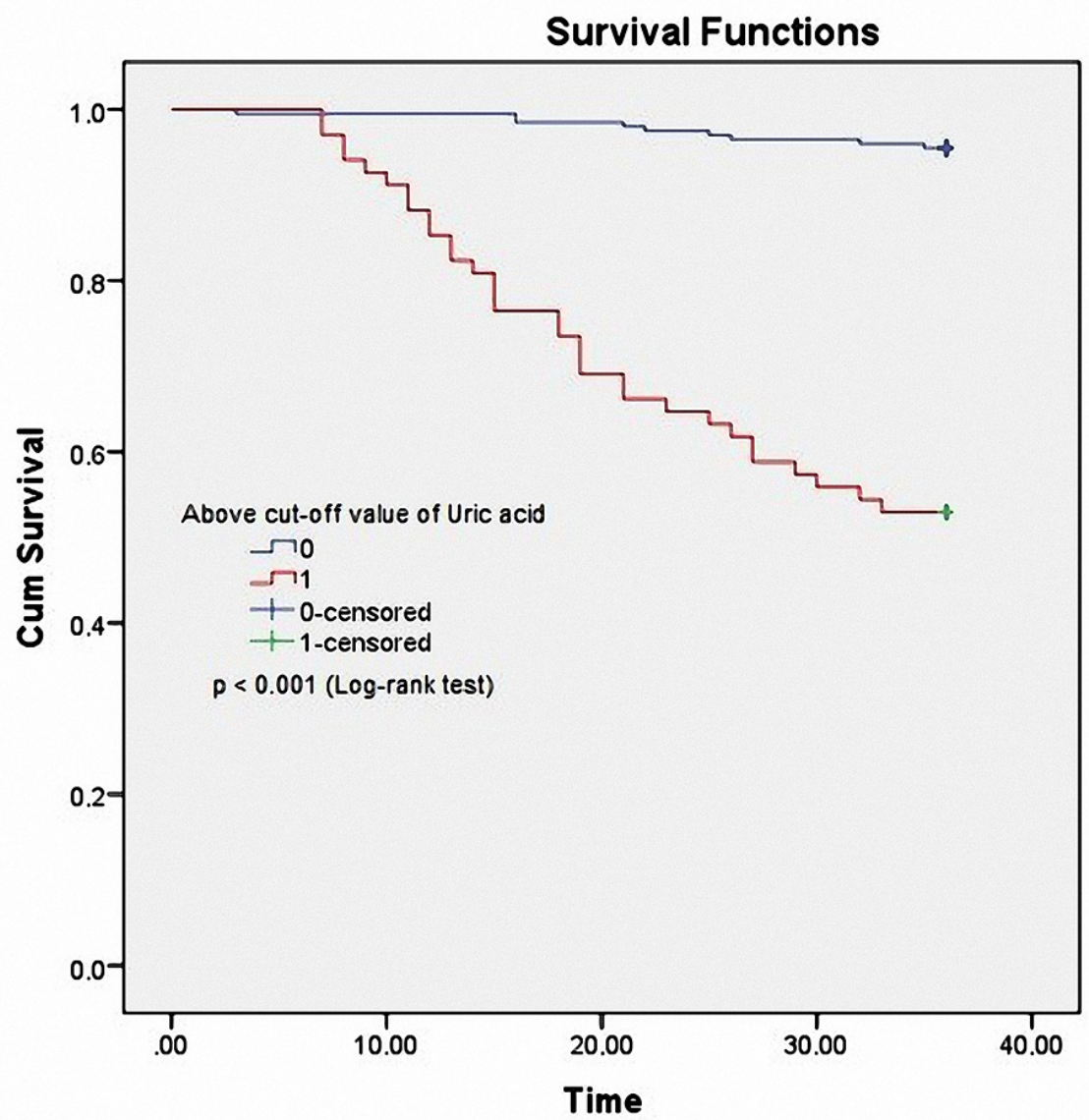

FIGURE 3: Kaplan-Meier analysis for all CAPD patients' mortality, classified according to UA level

UA: uric acid; CAPD: continuous ambulatory peritoneal dialysis

Similar to UA, the Kaplan-Meier analysis showed that patients with higher serum hs-CRP level (hs-CRP 》 $4.05 \mu \mathrm{mol} / \mathrm{L}$ : red line) had a significantly higher mortality rate than those with lower hs-CRP level (hs-CRP < $4.05 \mu \mathrm{mol} / \mathrm{L}$ : violet line) (Log-rank test, $\mathrm{p}<0.001$ ) (Figure 4). 


\section{Cureus}

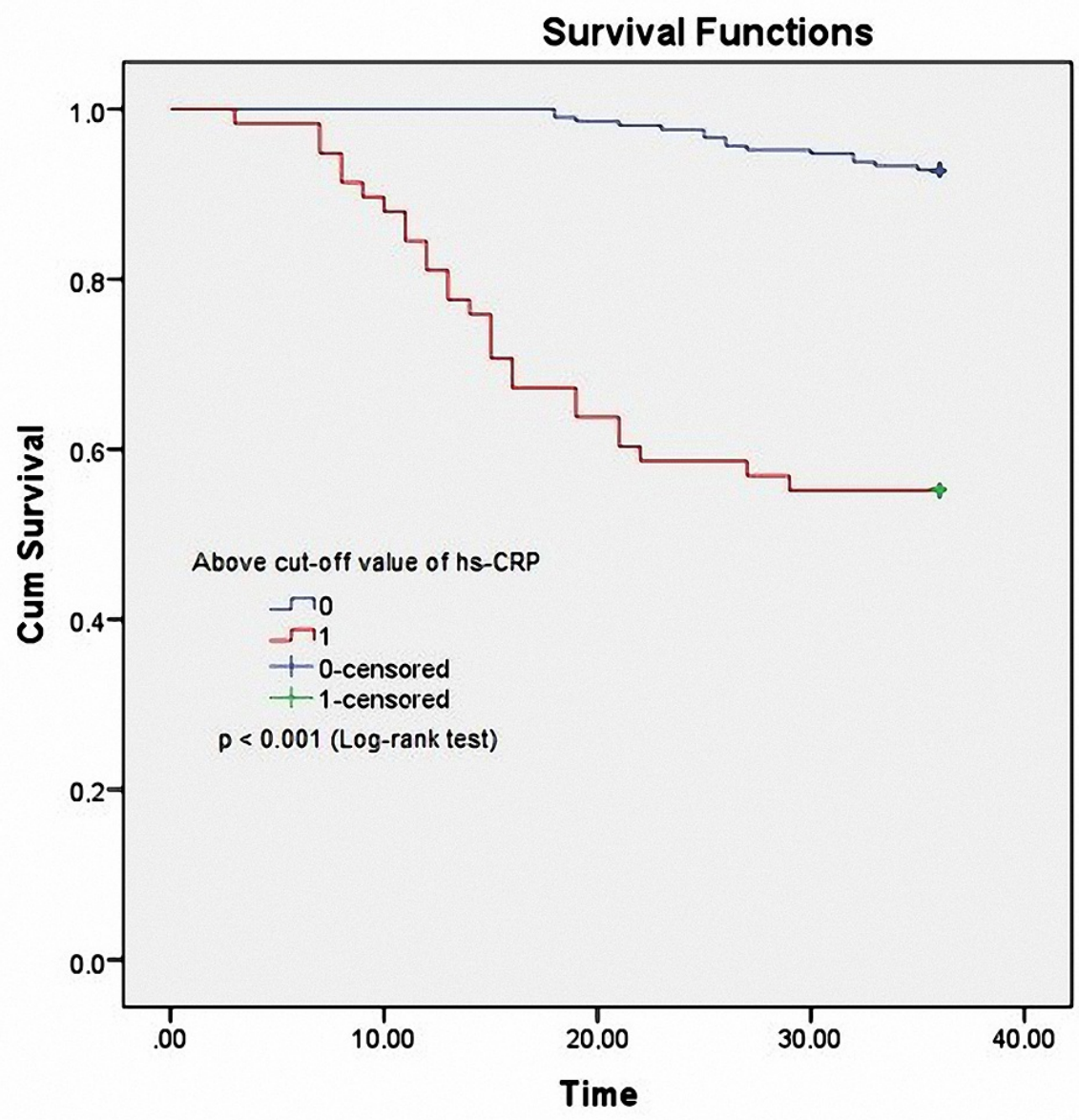

FIGURE 4: Kaplan-Meier analysis for all CAPD patients' mortality, classified according to serum hs-CRP concentration

CAPD: continuous ambulatory peritoneal dialysis; hs-CRP: high-sensitivity $\mathrm{C}$ reactive protein

\section{Discussion}

\section{The concentration of serum UA, hs-CRP, and ratio of mortality}

An increase in serum UA was reported in previous studies [17-20,25]. In non-dialysis chronic kidney disease (CKD) patients, the hyperuricemia rate ranged from 40 to $70 \%$ [26-28]. In dialysis patients, the ratio of hyperuricemia was $34.4 \%[25]$ and is related to the longer duration of hemodialysis or peritoneal dialysis [27]. Peritoneal membrane plays an essential role in removing UA from circulation in PD patients $[29,30]$. UA is a small molecular solute in its ionized form and is highly hydrophilic. UA is rapidly diffused through the peritoneal membrane to be efficiently purified by PD [31]. It explains that elevated serum UA ratio in dialysis patients was lower than non-dialysis CKD ones. As for serum UA, an increase of serum hs-CRP was reported in PD patients [7-10]. Fine [32] found 31\% of PD patients with increasing serum CRP. The majority of the unexplained increase in CRP levels in peritoneal dialysis patients is associated with atherosclerosis [32]. Atherosclerosis is a chronic inflammatory disease [33]. Atherosclerosis begins with a fatty streak, an accumulation of lipid-laden foam cells in the intimal layer of the artery. Lipid retention is the first step in atherosclerosis's pathogenesis, which is followed by chronic inflammation at susceptible sites in the artery walls $[33,34]$.

The ratio of cardiovascular-cause mortality was $15.4 \%$ in our study (Table 1 ) during three years of follow-up. Ye et al. [4] announced prevalence of all-cause mortality was 19.8\%, cardiovascular-related death was $11.13 \%$ in 1321 PD patients with a mean age of $48.1 \pm 15.3$ years, and $58.7 \%$ of males. The proportion of diabetes and history of cardiovascular diseases (CVD) was $23.5 \%$ and $36.3 \%$, respectively. Causes of death are almost related to peritonitis, CVD, malignant, cachexia in PD patients. Tsujikawa et al. [35] reported that the all-cause mortality ratio was $22.8 \%$, in which cardiovascular-related death reached $7.9 \%$ (48/606 patients). Dong et al. [18] showed that the ratio of cardiovascular-related mortality was $10.2 \%$ (231 patients) after evaluation in $2264 \mathrm{PD}$ patients (mean age of $58.1 \pm 15.5$ years). Thus, mortality from cardiovascular causes is common and accounts for a significant PD patient rate, just behind the infection's death rate. 


\section{Relationship between UA, hs-CRP, and cardiovascular-related mortality}

Our results showed some characteristics of PD patients relating to mortality, including hypertension, overweight, and obesity, DM, hypoprealbuminia, and anemia (Table 2, 3). Some previous studies have also confirmed the fact [36-39]. Thus, hypertension, DM, overweight, and obesity are risk factors and causes of many complications such as cerebrovascular disorders, myocardial ischemia, and peripheral artery disease. Elevated serum hs-CRP levels are a consequence of atherosclerosis, which is triggered by local inflammation in the arterial wall. On the other hand, serum hs-CRP increased closely to malnutrition, which occurred in $30-50 \%$ of PD patients $[40,41]$. Malnutrition directly leads to infection and death through weight loss, impaired immunity, and mucosal damage, which increases the risk of pathogen infiltration and complicates in patients treated with PD [41].

In the study, we found a relationship between high serum UA; hs-CRP and cardiovascular-related mortality. Our results also showed that UA and hs-CRP had good values for predicting cardiovascular-related mortality after 36 months of follow-up (Figure 2, 3, 4). UA is a potent antioxidant. Elevated UA levels can decrease nitric oxide (NO), endothelial disorders, atherosclerosis, etc. [42,43]. UA is an inexpensive, easy-to-perform biomarker that makes it very popular in clinical practice to assess cardiovascular risk factors. hs-CRP is a biological marker for evaluating nonspecific inflammation and has been widely used as a cardiovascular risk factor [44]. hs-CRP itself mediates atherothrombosis. Many recent studies have shown that hs-CRP is directly related to and predicts cardiovascular events $[16,44,45]$. UA and hs-CRP have been confirmed to predict all-cause mortality as well as infection-related mortality in PD patients in some previous studies $[4,5,14,15]$. Our results also demonstrate that clinicians can use serum UA and hs-CRP to predict cardiovascular-related mortality in CAPD patients.

\section{Limitations}

We think that the study results have met our research hypothesis, which is to use serum UA and hs-CRP (indices easily collected in clinical practice) to predict cardiovascular-related mortality in CAPD patients. However, there are still some limitations in this study. Firstly, this is a single-center descriptive observational study, so the characteristics of Vietnamese CAPD patients have not been fully described. Nextly, we did not analyze the relationship between residual renal function, peritoneal function, peritoneal filtration efficiency, and peritonitis with cardiovascular-related mortality.

\section{Conclusions}

In conclusion, the ratio of cardiovascular-related mortality was $15.4 \%$. The mean UA and the median hs-CRP concentration were significantly higher in the mortality group than in the survival group. Hypertension, diabetes, high serum UA and hs-CRP were independent risk factors related to mortality in CAPD patients.

High serum UA and hs-CRP concentrations were good predictors of cardiovascular-related mortality in CAPD patients based on the ROC curve model and Kaplan-Meier analysis.

\section{Additional Information}

\section{Disclosures}

Human subjects: Consent was obtained or waived by all participants in this study. The Ethical Committee of Cho Ray Hospital issued approval No.1378/QĐ/BVCR. Ethics approval: The Ethical Committee of Cho Ray Hospital has approved this study (No.1378/QĐ/BVCR). All procedures on humans followed the local ethical standards and the Helsinki Declaration of 1975 (revised in 2008). Consent to participate: All patients signed written informed consent before participating in this study. Animal subjects: All authors have confirmed that this study did not involve animal subjects or tissue. Conflicts of interest: In compliance with the ICMJE uniform disclosure form, all authors declare the following: Payment/services info: All authors have declared that no financial support was received from any organization for the submitted work. Financial relationships: All authors have declared that they have no financial relationships at present or within the previous three years with any organizations that might have an interest in the submitted work. Other relationships: All authors have declared that there are no other relationships or activities that could appear to have influenced the submitted work.

\section{Acknowledgements}

Dao Bui Quy Quyen and Pham Ngoc Huy Tuan are the first co-authors.

\section{References}

1. Andreoli MC, Totoli C: Peritoneal dialysis. Rev Assoc Med Bras (1992). 2020, 66:s37-44. 10.1590/18069282.66.S1.37

2. Mehrotra R, Devuyst O, Davies SJ, Johnson DW: The current state of peritoneal dialysis . J Am Soc Nephrol. 2016, 27:3238-52. 10.1681/ASN.2016010112

3. Krediet RT, Abrahams AC, de Fijter CW, et al.: The truth on current peritoneal dialysis: state of the art . Neth J Med. 2017, 75:179-89. 
4. Ye H, Zhou Q, Fan L, et al.: The impact of peritoneal dialysis-related peritonitis on mortality in peritoneal dialysis patients. BMC Nephrol. 2017, 18:186. 10.1186/s12882-017-0588-4

5. Okpechi IG, Ekrikpo U, Moloi MW, Noubiap JJ, Okpechi-Samuel US, Bello AK: Prevalence of peritonitis and mortality in patients with ESKD treated with chronic peritoneal dialysis in Africa: a systematic review. BMJ Open. 2020, 10:e039970. 10.1136/bmjopen-2020-039970

6. Moloi MW, Kajawo S, Noubiap JJ, et al.: Prevalence of peritonitis and mortality in patients treated with continuous ambulatory peritoneal dialysis (CAPD) in Africa: a protocol for a systematic review and metaanalysis. BMJ Open. 2018, 8:e020464. 10.1136/bmjopen-2017-020464

7. Seo SM, Baek SH, Jeon HK, et al.: Correlations between the level of high-sensitivity C-reactive protein and cardiovascular risk factors in Korean adults with cardiovascular disease or diabetes mellitus: the CALLISTO study. J Atheroscler Thromb. 2013, 20:616-22. 10.5551/jat.16089

8. Wang Z, Wang X, Chen Z, Zhang L, Zhu M: Distribution of high-sensitivity C-reactive protein and its relationship with other cardiovascular risk factors in the middle-aged Chinese population. Int J Environ Res Public Health. 2016, 13:10.3390/ijerph13090872

9. Ebrahimi M, Heidari-Bakavoli AR, Shoeibi S, et al.: Association of serum hs-CRP levels with the presence of obesity, diabetes mellitus, and other cardiovascular risk factors. J Clin Lab Anal. 2016, 30:672-6. $10.1002 /$ jcla.21920

10. Swastini DA, Wiryanthini IA, Ariastuti NL, Muliantara A: Atherosclerosis prediction with high sensitivity Creactive protein (hs-CRP) and related risk factor in patient with dyslipidemia. Open Access Maced J Med Sci. 2019, 7:3887-90. 10.3889/oamjms.2019.526

11. Andronesi A, Iliuta L, Patruleasa M, et al.: Predictive factors for coronary artery disease among peritoneal dialysis patients without diabetic nephropathy. Maedica (Bucur). 2012, 7:227-35.

12. Li W, Xiong L, Fan L, et al.: Association of baseline, longitudinal serum high-sensitive C-reactive protein and its change with mortality in peritoneal dialysis patients. BMC Nephrol. 2017, 18:211. 10.1186/s12882017-0624-4

13. Yang X, Zhang H, Shi Y, et al.: Association of serum angiopoietin-2 with malnutrition, inflammation, atherosclerosis and valvular calcification syndrome and outcome in peritoneal dialysis patients: a prospective cohort study. J Transl Med. 2018, 16:312. 10.1186/s12967-018-1687-0

14. Zhao G, Huang L, Song M, Song Y: Baseline serum uric acid level as a predictor of cardiovascular disease related mortality and all-cause mortality: a meta-analysis of prospective studies. Atherosclerosis. 2013, 231:61-8. 10.1016/j.atherosclerosis.2013.08.023

15. Rahimi-Sakak F, Maroofi M, Rahmani J, Bellissimo N, Hekmatdoost A: Serum uric acid and risk of cardiovascular mortality: a systematic review and dose-response meta-analysis of cohort studies of over a million participants. BMC Cardiovasc Disord. 2019, 19:218. 10.1186/s12872-019-1215-z

16. Wang J, Tan GJ, Han LN, Bai YY, He M, Liu HB: Novel biomarkers for cardiovascular risk prediction . J Geriatr Cardiol. 2017, 14:135-50. 10.11909/j.issn.1671-5411.2017.02.008

17. Feng S, Jiang L, Shi Y, et al.: Uric acid levels and all-cause mortality in peritoneal dialysis patients . Kidney Blood Press Res. 2013, 37:181-9. 10.1159/000350143

18. Dong J, Han QF, Zhu TY, et al.: The associations of uric acid, cardiovascular and all-cause mortality in peritoneal dialysis patients. PLoS One. 2014, 9:e82342. 10.1371/journal.pone.0082342

19. Xiang S, Zhang X, Xie X, et al.: High serum uric acid level is a mortality risk factor in peritoneal dialysis patients: a retrospective cohort study. Nutr Metab (Lond). 2019, 16:52. 10.1186/s12986-019-0379-y

20. Sugano N, Maruyama Y, Ohno I, et al.: Effect of uric acid levels on mortality in Japanese peritoneal dialysis patients. Perit Dial Int. 2021, 41:320-7. 10.1177/0896860820929476

21. La Milia V: Peritoneal transport testing. J Nephrol. 2010, 23:633-47.

22. Peritoneal Dialysis Adequacy 2006 Work Group: Clinical practice guidelines for peritoneal adequacy, update 2006. Am J Kidney Dis. 2006, 48:S91-7. 10.1053/j.ajkd.2006.05.016

23. Sarnak MJ, Bloom R, Muntner P, Rahman M, Saland JM, Wilson PW, Fried L: KDOQI US commentary on the 2013 KDIGO Clinical Practice Guideline for lipid management in CKD. Am J Kidney Dis. 2015, 65:354-66. 10.1053/j.ajkd.2014.10.005

24. Carrero JJ, de Jager DJ, Verduijn M, et al.: Cardiovascular and noncardiovascular mortality among men and women starting dialysis. Clin J Am Soc Nephrol. 2011, 6:1722-30. 10.2215/CJN.11331210

25. Hsieh YP, Chang CC, Kor CT, Yang Y, Wen YK, Chiu PF, Lin CC: Relationship between uric acid and technique failure in patients on continuous ambulatory peritoneal dialysis: a long-term observational cohort study. BMJ Open. 2017, 7:e010816. 10.1136/bmjopen-2015-010816

26. Dousdampanis P, Trigka K, Musso CG, Fourtounas C: Hyperuricemia and chronic kidney disease: an enigma yet to be solved. Ren Fail. 2014, 36:1351-9. 10.3109/0886022X.2014.947516

27. Murea M: Advanced kidney failure and hyperuricemia . Adv Chronic Kidney Dis. 2012, 19:419-24. 10.1053/j.ackd.2012.07.008

28. Chonchol M, Shlipak MG, Katz R, et al.: Relationship of uric acid with progression of kidney disease . Am J Kidney Dis. 2007, 50:239-47. 10.1053/j.ajkd.2007.05.013

29. Xiao X, Ye H, Yi C, et al.: Roles of peritoneal clearance and residual kidney removal in control of uric acid in patients on peritoneal dialysis. BMC Nephrol. 2020, 21:148. 10.1186/s12882-020-01800-1

30. Yang C, Ma X, Zhao W, et al.: A longitudinal analysis of the relationship between serum uric acid and residual renal function loss in peritoneal dialysis patients. Ren Fail. 2020, 42:447-54. 10.1080/0886022X.2020.1761387

31. Murea M, Tucker BM: The physiology of uric acid and the impact of end-stage kidney disease and dialysis . Semin Dial. 2019, 32:47-57. 10.1111/sdi.12735

32. Fine A: Relevance of C-reactive protein levels in peritoneal dialysis patients . Kidney Int. 2002, 61:615-20. 10.1046/j.1523-1755.2002.00145.x

33. Libby P: Inflammation in atherosclerosis. Nature. 2002, 420:868-74. 10.1038/nature01323

34. Wolf D, Ley K: Immunity and inflammation in atherosclerosis . Circ Res. 2019, 124:315-27. 10.1161/CIRCRESAHA.118.313591

35. Tsujikawa H, Tanaka S, Matsukuma Y, et al.: Development of a risk prediction model for infection-related 


\section{Cureus}

mortality in patients undergoing peritoneal dialysis. PLoS One. 2019, 14:e0213922.

10.1371/journal.pone.0213922

36. Wei X, Wen Y, Zhou Q, et al.: Hyperlipidemia and mortality associated with diabetes mellitus co-existence in Chinese peritoneal dialysis patients. Lipids Health Dis. 2020, 19:234. 10.1186/s12944-020-01405-5

37. Dahlinghaus EK, Neu AM, Atkinson MA, Fadrowski JJ: Hemoglobin level and risk of hospitalization and mortality in children on peritoneal dialysis. Pediatr Nephrol. 2014, 29:2387-94. 10.1007/s00467-014-2872-x

38. Lee $\mathrm{KH}$, Cho JH, Kwon O, et al.: Low prealbumin levels are independently associated with higher mortality in patients on peritoneal dialysis. Kidney Res Clin Pract. 2016, 35:169-75. 10.1016/j.krcp.2016.06.002

39. Ye M, Li J, Liu Y, et al.: Serum prealbumin and echocardiography parameters predict mortality in peritoneal dialysis patients. Kidney Blood Press Res. 2020, 45:671-85. 10.1159/000507331

40. Satirapoj B, Limwannata P, Kleebchaiyaphum C, Prapakorn J, Yatinan U, Chotsriluecha S, Supasyndh O: Nutritional status among peritoneal dialysis patients after oral supplement with ONCE dialyze formula . Int J Nephrol Renovasc Dis. 2017, 10:145-51. 10.2147/IJNRD.S138047

41. Kiebalo T, Holotka J, Habura I, Pawlaczyk K: Nutritional status in peritoneal dialysis: nutritional guidelines, adequacy and the management of malnutrition. Nutrients. 2020, 12:1715. 10.3390/nu12061715

42. Gagliardi AC, Miname MH, Santos RD: Uric acid: a marker of increased cardiovascular risk . Atherosclerosis. 2009, 202:11-7. 10.1016/j.atherosclerosis.2008.05.022

43. Vassalle C, Mazzone A, Sabatino L, Carpeggiani C: Uric acid for cardiovascular risk: Dr. Jekyll or Mr. Hide? . Diseases. 2016, 4:12. 10.3390/diseases4010012

44. Kaptoge S, Di Angelantonio E, Lowe G, Pepys MB, Thompson SG, Collins R, Danesh J: C-reactive protein concentration and risk of coronary heart disease, stroke, and mortality: an individual participant metaanalysis. Lancet. 2010, 375:132-40. 10.1016/S0140-6736(09)61717-7

45. Elliott P, Chambers JC, Zhang W, et al.: Genetic loci associated with C-reactive protein levels and risk of coronary heart disease. JAMA. 2009, 302:37-48. 10.1001/jama.2009.954 